\title{
Surviving Work from Home: Observations from Singapore
}

\author{
Tiffany Nicole Danker ${ }^{1} \cdot$ Hui Lin Yap ${ }^{1} \cdot$ Alyah Dinah Zalzuli $^{1} \cdot$ Hui Fen $\mathrm{Ho}^{1} \cdot$ Jansen Ang ${ }^{1}$ (D)
}

Accepted: 25 May 2021 / Published online: 23 July 2021

(c) Society for Police and Criminal Psychology 2021

\begin{abstract}
Circuit Breaker measures were implemented in Singapore on 7 April 2020, and work from home arrangements were officially made compulsory for most due to COVID-19. This study assessed the effects of prolonged telecommuting within the Singapore Police. Items on productivity, satisfaction with telecommuting, work-life effectiveness, feelings of safety, stress levels, connectedness to and support by colleagues, and supervisors were included. The study found that while prolonged telecommuting did not have any impact on levels of satisfaction with telecommuting, individuals with caregiving duties were significantly less satisfied with telecommuting than non-caregivers. Implications of the findings were discussed with respect to the necessary support required by officers while telecommuting. Recommendations on how individuals can practice selfcare while telecommuting for prolonged periods were also proposed.
\end{abstract}

Keywords Telecommute $\cdot$ Telework $\cdot$ COVID-19 $\cdot$ Productivity $\cdot$ Satisfaction $\cdot$ Support $\cdot$ Stress

\section{Introduction}

The Coronavirus Disease 2019 (COVID-19), first identified in December 2019, in Wuhan, Hubei, China, has since spread worldwide and is now considered by the United Nations (UN) as the worst global crisis since World War II. The world has been experiencing a global pandemic for months with no definite end in sight. To fight COVID-19, several countries, such as Spain, Germany, South Korea, and China, have implemented drastic measures, such as lockdowns. Likewise, Singapore entered a Circuit Breaker on 7 April 2020 to reduce the community spread of the virus. Work from home, otherwise known as telecommuting, was officially mandated nationwide with few exceptions. It was a new state of normal for all, including the Singapore Police.

Singapore is an island city-state in Southeast Asia. Many individuals know the country as the "Red Dot" on the world map, surrounded by water. Singapore is a multi-ethnic country with four main ethnicities-Chinese, Malay, Indians, and Eurasians. The Singapore Police is the main law enforcement agency in Singapore, which was formed in 1819 with

\footnotetext{
Jansen Ang

Jansen_Ang@spf.gov.sg

1 Police Psychological Services Division, Singapore Police Force, Singapore, Singapore
}

12 officers. It has since grown into an organisation with 15,000 regular officers, civilian staff, and National Servicemen. As restrictions eased and Singapore entered Phase 1 on 3 June 2020 and thereafter Phase 2 on 19 June 2020, telecommuting remained the default for non-frontline officers in SPF who were able to telecommute. What, then, are the effects of such prolonged telecommuting?

There has been an abundance of literature on telecommuting, its effects on job satisfaction, and productivity, as well as the different factors involved. Given the fast-paced advancements in technology, the literature review comprised research studies assessing the drivers and constraints of telecommuting that were conducted in the past decade. Telecommuting studies that were carried out during COVID-19 were also taken into consideration.

Organizational, personal, and environmental benefits of telecommuting have been widely discussed in multiple research studies. A comprehensive meta-analysis conducted by Allen et al. (2015) investigated the impact of telecommuting on several work-related outcomes. In general, the meta-analysis found that telecommuting is positively associated with job satisfaction, organizational commitment and identification, and supervisor-rated or objectively measured job performance. Similarly, organizations that allowed individuals the option to telecommute saw an increase in worker engagement, perceived supervisor support, and productivity (Masuda et al. 2017; Harker and MacDonnell 2012). 
Additionally, when telecommuting was highly normative in a given work context, extensive telecommuters received more promotions, though the best career benefits were reaped by the occasional telecommuter (Golden and Eddleston 2020).

Telecommuters believed that the experience made them feel healthier and relieved, and would rather give up their favorite food and a portion of their salary than telecommuting (Zia and Bilal 2017). Findings by Raghuran (2014) highlighted reduced traffic congestion and commuter hassles as some of the pros of telecommuting in India. When analyzing the effects of early experiences of working from home in the COVID-19 situation in Europe, Ipsen and Hansen (2020) found that the benefits of telecommuting included working in a preferred environment, saving on transport time and cost, and having more control over their working day. This is congruent with pre-COVID findings in a study by O'Keefe et al. (2016), which investigated the impact of telecommuting in Dublin and found that telecommuting reduced the number of trips or travelled distances of the respondents and allowed them to use the time saved for leisure, work, or household tasks.

Although working from home has been perceived to be beneficial in many regards, there also lies a plethora of research showcasing the negative psychological impacts of working from home. Remote workers have reported higher stress levels, work-role stress, and work exhaustion than office workers (European Nations 2017; Allen et al. 2015). This may be attributed to the following reasons. First, social and professional isolation are derived as one of the primary concerns resulting from telecommuting. As working remotely may be associated with an "out of sight, out of mind" mentality and affect visibility, this can breed a lack of trust between workers and supervisors (Leslie et al. 2012; Maruyama and Tietze 2012; Grenny and Maxfield 2017). Employees who telecommute may suffer lower performance evaluation as a result of their absence from the office (Elsbach and Cable 2012).

Additionally, telecommuting may lead to an increase in work-family conflict. A study on German telecommuters by Sarbu (2018) found a positive relationship between telecommuting and work-family conflict, as telecommuting and intensive telecommuting decrease the probability for employees to reconcile personal and professional interests. Work-family conflict may arise when home roles and activities interfere with work demands while telecommuting. Delanoeije et al. (2019) found that employees had to interrupt their work activities to deal with home demands more often during telecommuting days, possibly because employees may take on a larger portion of home roles and activities when working from home. The extent to which home roles and activities impact work performance may be dependent on the employee's family structures. Family structures that encompass a spouse who stays at home to take care of children or living arrangements that include extended or joint family members (e.g., parents-in-law, elderly parents) may dilute the effectiveness of telecommuting (Raghuram 2014). Allen et al. (2015) acknowledged that the impact of telecommuting may be moderated by various factors, such as gender, the presence of caregiving duties, and the length of telecommuting. Specifically, for gender, Mas and Pallais (2017) found that women who had children were more inclined to take salary cuts in exchange for flexibility in their working hours.

Work-family conflict may also arise when work roles and activities interfere with home demands while telecommuting. Individuals who telecommute may have difficulties managing the boundaries between their work and personal lives. As these lines get increasingly blurred, individuals may find themselves working longer hours, enjoying lesser free time and experiencing burnout quicker (Allvin et al. 2011). This is also supported by Delanoeije et al. (2019), who found that employees continue to participate in work roles and activities after office hours more often on telecommuting days. Working overtime may have adverse effects on family dynamics as individuals harbor guilt for neglecting their families. Rising family disputes may then cause additional stress to these individuals (Ojala 2011; Sullivan 2012).

In the COVID-19 context, participants struggled with the isolation that resulted from telecommuting, concentration, and the lack of work tools (i.e., documents, physical equipment). Congruent with pre-COVID-19 findings, individuals falling under the 'sandwich generation' who telecommuted 5 days a week worked longer hours as they had to juggle caring for their children and parents (Putro and Riyanto 2020).

As can be seen, existing studies have attempted to explore the effects of telecommuting as well as the different factors involved. However, there are two key features of these studies that reduce the generalizability of their findings to the current context. First, existing studies in the literature generally involve participants who are telecommuting voluntarily and on an ad hoc basis. For example, Golden (2006) studied employees who telecommuted voluntarily from between 2 to over 35 hours a week. In another study, the sample included participants who spent $23 \%$ of the week telecommuting on average (Golden and Veiga 2005). As such, the results of existing studies may not be generalizable to the current context of mandated, prolonged telecommuting in the Police.

Second, the nature of work of the respondents in existing studies may be vastly different from those of SPF. For example, respondents of Golden and Veiga's (2005) study held positions in systems analysis, marketing, programming, engineering, accounting, and sales. The nature of these positions differs largely from the operational nature of police work, which is often dynamic and fast-paced. Furthermore, police officers continue to fight crime with the added challenges of policing during a pandemic. Beyond the policing role, the 
Singapore Police is also substantially involved in the fight against COVID-19, with police officers being deployed at Government Quarantine Facilities (GQFs), localized quarantine facilities, at the frontline, in contact tracing operations, or in staff departments working to support crisis operations in the background with civilian officers. As such, the results of existing studies may not sufficiently capture the effects of prolonged telecommuting within the Singapore Police due to the unique challenges faced by police officers.

This paper therefore hopes to fill the gaps in the existing literature by studying the effect of prolonged telecommuting within the Singapore Police. Specifically, this paper hopes to (1) identify salient challenges faced by staff officers who have been consistently telecommuting since the commencement of the Circuit Breaker; (2) examine the impact of gender, caregiving duties and length of telecommuting on the productivity, general well-being and satisfaction of these officers; and (3) identify areas for improvement or enhanced organizational support for telecommuting arrangements. The results of the study will inform police organizations on how to better prepare for prolonged telecommuting arrangements in future situations. It is important to note that as telecommuting during COVID-19 is a recent phenomenon, there is a limit to how much existing work psychology theories can explain this phenomenon.

\section{Method}

\section{Participants}

Data was collected at four different time points from the same population of police officers. As the survey was completed on a voluntary and anonymous basis, it was not possible to track the survey completion of a single officer across the four different time points. As such, each time point was treated as a separate sample. In total, 2024 responses were collected and used for analysis. The breakdown of the participants can be found in Table 1 of the Appendix.

\section{Procedures}

At each time point, an online survey was administered to officers in staff departments who had been consistently telecommuting since the commencement of the Circuit Breaker. This was conducted via an online platform known as FormSG, which is a government-friendly version of Google Form that was developed by GovTech-a government technology enabling agency in Singapore. The survey link was disseminated via email and/or WhatsApp, according to the preference of the Point-of-Contact (POC) of each staff department.

At the start of the survey, demographic information of the participants was collected, such as gender, unit or department, scheme of service, and presence of caregiving duties.
Participants were asked to specify the type of caregiving duties. For this study, caregiving duties were defined as taking care of children, elderly, and/or disabled persons. Participants indicating other responses, such as pets, were reclassified as non-caregivers.

To measure the participants' productivity level while telecommuting, participants were asked to rate four items shown below on a 5-point Likert scale from 1 (Strongly Disagree) to 5 (Strongly Agree).

Items measuring productivity level

I am more productive than in office

I am more distracted than in office.

I work longer hours than in office.

My home is more conducive for work than in office.

To measure the participants' general well-being while telecommuting, participants were asked to rate nine items shown below on a 5-point Likert scale from 1 (Strongly Disagree) to 5 (Strongly Agree).

Items measuring general well-being

I feel connected to my colleagues

I feel connected to my supervisors.

I am supported by my colleagues.

I am supported by my supervisors.

I am able to keep work and personal life separate.

I am able to maintain work-life effectiveness.

I feel better able to manage stress.

I am less stressed.

In light of the COVID-19 situation, I feel less at risk of infection

To measure the participants' satisfaction with telecommuting, participants were asked to rate their current level of satisfaction with telecommuting on a 5-point Likert scale from 1 (Very Low) to 5 (Very High). Participants were also asked to indicate what they liked about telecommuting and the challenges they faced while telecommuting.

Finally, qualitative data was collected by asking participants to indicate if there were any areas of improvement or organizational support required during the telecommuting arrangements.

\section{Results}

\section{Comparison of Gender and Prolonged Telecommuting}

Statistical analyses were conducted using Statistical Package for Social Sciences (SPSS) version 24.0. Independent sample $t$-tests were conducted to evaluate for any significant 
differences on officers' perceived effectiveness of telecommuting between gender. Cohen's $d$ was then applied after the $t$-test analyses to evaluate the strength of association between the variables as explored in the $t$-test. Simple effects analyses showed that there was no significant difference in officers' perceived effectiveness of telecommuting between male $(M=3.88, S D=0.92)$ and female $(M=3.94, S D=0.80)$ officers, $t(1962.01)=-1.39, p=0.164, d=0.07$ (very small effect size). For Cohen's $d$, an effect size of 0.01 to 0.2 is considered a "very small" effect (Sawilowsky 2009).

\section{Effects of Gender and Caregiving Duties on Respective Domains}

Two-way ANOVA was conducted to find out if there were any effects of gender and caregiving duties on the respective domains. A simple main effect analyses was also done when there was a significant interaction between the two independent variables on the 14 domains. Analyses found that 5 out of 14 domains showed a significant interaction between the variables (i.e., productivity, length of working hours, work conduciveness at home, safety (i.e., from risk of infection), and overall satisfaction). Additionally, while there was no significant interaction for the domain on feelings of supported by supervisors, the simple main effects analysis reported to have a significant difference between gender caregiving duties on the said domain. Descriptive statistics on gender and their caregiver role, as well as the table of values for the analysis of variance on all domains, are shown in Tables 1, 2, 3, 4, 5, 6, 7, 8, 9, 10, 11, 12, 13, 14,15 and 16.

Productivity There was a significant interaction between the effects of gender and caregiving duties on the productivity level, $F(1,2019)=5.59, p<0.05$. The main effect analysis showed that males with no caregiving duties $(M=3.53$, $S D=0.04)$ were significantly less productive than females with no caregiving duties $(M=3.73, S D=0.05)$, but there were no differences between gender with caregiving duties $(p=0.91)$.

Distraction There was no significant interaction between the effects of gender and caregiving duties on the productivity level, $F(1,2019)=0.03, p=0.87$.

Length of Working Hours There was a significant interaction between the effects of gender and caregiving duties on the length of working hours, $F(1,2019)=5.22, p<0.05$. The main effect analysis showed that females with $(M=3.54$, $S D=0.05)$ and without $(M=3.59, S D=0.05)$ caregiving duties work significantly longer hours than males with
$(M=3.39, S D=0.04)$ and without $(M=3.21, S D=0.05)$ caregiving duties.

Work Conduciveness at Home There was a significant interaction between the effects of gender and caregiving duties on the work conduciveness at home, $F(1,1463)=5.56, p<0.05$. The main effect analysis showed that males with no caregiving duties $(M=3.23, S D=0.05)$ found their homes to be significantly less conducive than females with no caregiving duties $(M=3.44, S D=0.06)$, but there were no differences between gender with caregiving duties $(p=0.91)$.

Feelings of Connectedness to Colleagues. There was no significant interaction between the effects of gender and caregiving duties on the feelings of connectedness to colleagues, $F(1,2019)=2.02, p=0.16$.

Feelings of Connectedness to Supervisors There was no significant interaction between the effects of gender and caregiving duties on the feelings of connectedness to colleagues, $F(1,2019)=0.10, p=0.76$.

Feelings of Supported by Colleagues There was no significant interaction between the effects of gender and caregiving duties on the feelings of connectedness to colleagues, $F(1$, 2019) $=0.53, p=0.47$.

Feelings of Supported by Supervisors There was no significant interaction between the effects of gender and caregiving duties on the feelings of connectedness to colleagues, $F(1,2019)=0.22, p=0.64$. However, main effect analysis showed that females with $(M=3.53, S D=0.04)$ and without $(M=3.69, S D=0.04)$ caregiving duties felt significantly less supported than males with $(M=3.72, S D=0.04)$ and without $(M=3.84, S D=0.04)$ caregiving duties.

Work-Life Separation There was no significant interaction between the effects of gender and caregiving duties on the perception of work-life separation, $F(1,2019)=0.08$, $p=0.79$.

Work-Life Effectiveness There was no significant interaction between the effects of gender and caregiving duties on the perception of work-life effectiveness, $F(1,2019)=1.65$, $p=0.20$.

Stress Management There was no significant interaction between the effects of gender and caregiving duties on the stress management, $F(1,2019)=0.84, p=0.36$.

Stress Leve There was no significant interaction between the effects of gender and caregiving duties on the stress level, $F(1,1463)=0.15, p=0.70$. 
Safety (i.e., from Risk of Infection) There was a significant interaction between the effects of gender and caregiving duties on the feelings of safety, $F(1,2018)=7.90, p=0.05$. The main effect analysis showed that males with no caregiving duties $(M=4.26, S D=0.04)$ felt significantly less safe than females with no caregiving duties $(M=4.49$, $S D=0.04)$, but there were no differences between gender with caregiving duties $(p=0.98)$.

Satisfaction There was a significant interaction between the effects of gender and caregiving duties on the feelings of satisfaction with telecommuting, $F(1,2017)=5.02, p<0.05$. The main effect analysis showed that males with no caregiving duties $(M=3.95, S D=0.04)$ felt significantly less satisfied than females with no caregiving duties $(M=4.08$, $S D=0.04$ ), but there were no differences between gender with caregiving duties $(p=0.42)$.

\section{Effects of Caregiving Duties and Prolonged Telecommuting on Respective Domains}

Two-way ANOVA was also conducted to ascertain if there were any effects of caregiving duties and prolonged telecommuting on the respective domains. Post hoc analyses were also done when a significant effect between the number of weeks and aforementioned domains was found. Analyses found that there was no significant interaction between the effects of weeks of telecommuting and caregiving duties on the 14 domains. However, from the simple main effects analysis, significant effects were reported between caregivers and non-caregivers on most domains, except length of working hours and feelings of connectedness to colleagues. Descriptive statistics on caregiver roles and the table of values for the analysis of variance on all domains were shown in Tables 17, 18, 19, 20, 21, 22, 23, 24, 25, 26, 27, 28, 29, 30,31 and 32 .

Productivity The main effect of caregivers was statistically significant, $F(1,2015)=29.58, p<0.001$. Caregivers $(M=3.39, S D=0.93)$ were found to be significantly less productive as compared to non-caregivers $(M=3.62$, $S D=0.91)$.

Distraction The main effect of caregivers was statistically significant, $F(1,2015)=85.58, p<0.001$. Caregivers $(M=2.89, S D=1.10)$ were found to be significantly more distracted as compared to non-caregivers $(M=2.45$, $S D=1.05)$.

Length of Working Hours The main effects analysis showed that there was no effect on length of working hours between caregivers $(M=3.45, S D=1.08)$ and non-caregivers $(M=3.39, S D=1.09)$.
Work Conduciveness at Home The main effect of caregivers was statistically significant, $F(1,1461)=11.69, p<0.05$. Caregivers $(M=3.13, S D=1.07)$ were found to report significantly lower work conduciveness at home as compared to non-caregivers $(M=3.32, S D=0.96)$.

Feelings of Connectedness to Colleagues Simple main effects analysis showed that there was no effect on feelings of connectedness to colleagues between caregivers $(M=3.32$, $S D=0.10)$ and non-caregivers $(M=3.36, S D=0.96)$.

Feelings of Connectedness to Supervisors The main effect of caregivers was statistically significant, $F(1,2015)=3.97$, $p<0.05$. Caregivers $(M=3.32, S D=1.02)$ were found to report significantly lower feelings of connectedness to supervisors as compared to non-caregivers $(M=3.41, S D=0.93)$.

Feelings of Supported by Colleagues The main effect of caregivers was statistically significant, $F(1,2015)=4.20$, $p<0.05$. Caregivers $(M=3.70, S D=0.89)$ were found to report significantly lower feelings of supported by colleagues as compared to non-caregivers $(M=3.79, S D=0.87)$.

Feelings of Supported by Supervisors The main effect of caregivers was statistically significant, $F(1,2015)=8.53$, $p<0.05$. Caregivers $(M=3.65, S D=0.94)$ were found to report significantly lower feeling of supported by supervisors as compared to non-caregivers $(M=3.77, S D=0.88)$.

Work-Life Separation The main effect of caregivers was statistically significant, $F(1,2015)=27.00, p<0.001$. Caregivers $(M=3.48, S D=1.07)$ were found to report significantly lower effectiveness on work-life separation as compared to non-caregivers $(M=3.72, S D=0.97)$.

Work-Life Effectiveness The main effect of caregivers was statistically significant, $F(1,2015)=15.56, p<0.001$. Caregivers $(M=3.58, S D=1.04)$ were found to report significantly lower work-life effectiveness as compared to noncaregivers $(M=3.76, S D=0.96)$.

Stress Management The main effect of caregivers was statistically significant, $F(1,2015)=11.77, p<0.05$. Caregivers $(M=3.58, S D=0.99)$ were found to report significantly lower stress management as compared to non-caregivers $(M=3.73, S D=0.91)$.

Stress Level The main effect of caregivers was statistically significant, $F(1,1461)=10.20, p<0.05$. Caregivers $(M=3.39, S D=1.05)$ were found to report significantly higher stress level as compared to non-caregivers $(M=3.57$, $S D=1.02)$. 
Safety (i.e., from Risk of Infection) The main effect of caregivers was statistically significant, $F(1,2014)=17.50$, $p<0.001$. Caregivers $(M=4.20, S D=0.98)$ were found to report significantly lower feelings of safety as compared to non-caregivers $(M=4.37, S D=0.83)$.

Satisfaction The main effect of caregivers was statistically significant, $F(1,2014)=24.52, p<0.001$. Caregivers $(M=3.82, S D=0.89)$ were found to report significantly lower satisfaction with telecommuting as compared to noncaregivers $(M=4.01, S D=0.83)$.

In terms of the effect of length of telecommuting, analysis found that significant effect was reported between weeks of telecommuting on three domains-stress management, $F(3,2015)=2.70, p<0.05$; stress level, $F(2,1461)=4.26$, $p<0.05$; and safety, $F(3,2014)=7.60, p<0.01$, as shown in Tables 3, 4 and 5, respectively. Post hoc analyses were then conducted, where significant differences were observed for above domains. Stress management in Week $3(M=3.55$, $S D=0.94$ ) was found to be significantly lower than in Week $1(M=3.71, S D=0.97)$. This is further backed up by the significantly lower stress level in Week $3(M=3.37, S D=1.03)$, as compared to Week $2(M=3.54, S D=1.07)$ and Week 4 $(M=3.54, S D=1.00)$. On the other hand, officers reported a significantly higher feelings of safety in Week $1(M=4.42$, $S D=0.87)$, as compared to Week $3(M=4.16, S D=0.93)$ and Week $4(M=4.23, S D=0.93)$. Descriptive statistics on length of weeks are represented in Table 3 of the Appendix.

There was a marginally significant effect between weeks of telecommuting on two domains-distraction, $F(3$, $2015)=2.11, p=0.10$, and work-life effectiveness, $F(3$, $2015)=2.11, p=0.10$. Other domains like productivity, length of working hours, and satisfaction were not found to have any significance with prolonged telecommuting. The table of values for the analysis of variance on all domains can be found in the Appendix.

\section{Relationship Between the 14 Domains}

Pearson's correlation coefficient was run to determine the relationship between the 14 domains. While 9 out 14 domains showed to have a strong correlation between each other, 2 domains (i.e., distraction and longer hours) were found to have low correlation with most of the domains. The table of values for the Pearson correlation on all domains are shown in Table 33.

Productivity There was a strong, positive correlation between productivity and work conduciveness, $r(1465)=0.58, p<0.01$, and satisfaction, $r(2019)=0.51$, $p<0.01$.
Work Conduciveness at Home There was a strong, positive correlation between work conduciveness and satisfaction, $r(1464)=0.53, p<0.01$.

Feelings of Connectedness with Colleagues There was a strong, positive correlation between feelings of connectedness with colleagues and connectedness with supervisors, $r(2021)=0.82, p<0.01$; feelings of supported by colleagues, $r(2021)=0.66, p<0.01$; and supervisors, $r(2021)=0.54$, $p<0.01$.

Feelings of Connectedness with Supervisors There was a strong, positive correlation between feelings of connectedness with supervisors and feelings of supported by colleagues, $r(2021)=0.62, p<0.01$, and supervisors, $r(2021)=0.70, p<0.01$.

Feelings of Supported by Colleagues There was a strong, positive correlation between feelings of supported by colleagues and supported by supervisors, $r(2021)=0.75$, $p<0.01$, and work-life effectiveness, $r(2021)=0.50, p<0.01$.

Work-Life Separation There was a strong, positive correlation between work-life separation and work-life effectiveness, $r(2021)=0.83, p<0.01$; stress management, $r(2021)=0.68, p<0.01$; stress level, $r(2021)=0.59$, $p<0.01$; and satisfaction, $r(2021)=0.56, p<0.01$.

Work-Life Effectiveness There was a strong, positive correlation between work-life effectiveness and stress management, $r(2021)=0.74, p<0.01$, stress level, $r(1465)=0.65$, $p<0.01$, and satisfaction, $r(2019)=0.61, p<0.01$.

Stress Management There was a strong, positive correlation between stress management and stress level, $r(1465)=0.79$, $p<0.01$, and satisfaction, $r(2019)=0.60, p<0.01$.

Stress Level There was a strog, positive correlation between stress level and satisfaction, $r(1464)=0.58, p<0.01$.

A mixture of content and thematic analysis was conducted on the participants' responses to identify, analyse and interpret the patterns for three groups of officers (overall, caregivers, and non-caregivers) on three domains-likes, challenges, and areas of support for more effective telecommuting. Content analysis-wise, data was coded, and quantitative counts of each code were included in the findings. The thematic analysis was done in accordance to the protocol as proposed by Braun and Clarke (2006), which includes five broad phases: (1) familiarization with data, (2) generation of initial codes, (3) searching for themes, (4) defining and naming themes, and (5) reporting. 
Three independent coders first familiarized themselves with the participants' responses for Week 1. Various themes for each domain were then identified across the responses, and a set of keywords was generated to form the coding criteria for each domain. Based on the criteria, an independent coder went through each response to search for keywords, compared the response against a number of themes, and assigned a value of " 1 " under the theme should the response contain a keyword belonging to that theme. An example has been shown below:

\begin{tabular}{|c|c|c|c|c|c|}
\hline \multicolumn{6}{|c|}{ What do you like about telecommuting? } \\
\hline \multirow[t]{2}{*}{ Response } & \multicolumn{5}{|l|}{ Themes } \\
\hline & Flexibility & Transport & Health & Family & Productivity \\
\hline $\begin{array}{l}\text { Less risk of } \\
\text { exposure, } \\
\text { no com- } \\
\text { muting, } \\
\text { produc- } \\
\text { tive }\end{array}$ & & $\begin{array}{l}1 \text { (keyword: } \\
\text { commut- } \\
\text { ing) }\end{array}$ & $\begin{array}{l}1 \text { (keywords: } \\
\text { risk of } \\
\text { exposure) }\end{array}$ & & $\begin{array}{l}1 \text { (keyword: } \\
\text { produc- } \\
\text { tive) }\end{array}$ \\
\hline
\end{tabular}

For the first domain (Likes of telecommuting), there were five main themes-flexibility, transportation, health, family, and productivity. The second domain (Challenges of telecommuting) had six main themes-logistics, environment, technology, communication, productivity, and management support. Finally, the last domain (Areas of support) had four main themes-logistics, technology, productivity, and management support. The breakdown of the top three themes for respective groups is presented in Table 34 .

What Officers Liked About Telecommuting. Overall, top three themes that officers appreciated were the flexibility $(61.9 \%)$ of working from home (e.g., "Can flexibly adjust schedule so I work when I am productive (e.g., Push lunch backwards because more productive in morning"), the time and money saved on transportation (46.4\%) (e.g., "Savings on transport, time, and meals."), and health considering the situation with COVID-19 (42.7\%) (e.g., "Amidst the current covid19 situation, I think the telecommuting option provides us with greater health assurance against the risk of infection."). On the other hand, family (43.9\%) was chosen as one of the top three themes officers with caregiving duties appreciated on telecommuting (e.g., "Flexibility of being able to fulfil work and parenting duties at the same time").

What Officers Found Challenging About Telecommuting. Overall, top three themes that officers found challenging about working from home were logistics (22.9\%) (e.g., "Lack of logistic items such as printer, scanner and etc. to carry out work."), technology (22.5\%) (e.g., "Certain bespoke enterprise IT systems are not accessible via VPN."), and environment (22.3\%) (e.g., "Lack of proper work station."). The themes were consistent for officers with or without caregiving duties.
Additional Support Officers Require for Prolonged Telecommuting. Overall, top three themes that officers require additional support for were technology (17.4\%) (e.g., "To provide a secure form of telecommunication between SPF and vendors."), logistics (12.2.\%) (e.g., "If portable monitor can be provided, this will aid in employee while work from home."), and management support (11.9\%) (e.g., "For understanding that flexi hours are required too due to childcare needs."). The themes were consistent for officers with or without caregiving duties.

\section{Discussion}

The present study sought to assess the effects of prolonged telecommuting in the Singapore Police based on facets including satisfaction, productivity, and health. The study found that gender was not a key differentiating factor in determining the effects of telecommuting (i.e., male and female officers reported similar levels of satisfaction with telecommuting). This ran contrary to other studies conducted on telecommuting, which reported that females have lower levels of productivity (Allen et al. 2015; Kraut 1989). A reason for this may be because gender does not influence the type of stressors faced by police officers. A study conducted on police officers by Gatcher et al. (2011) found that gender did not play a role in majority of the categorical stressors (i.e., psychological strain, overall strain, anxiety, depression, and burnout). It is therefore possible that working in a police organization negates the effects of gender, thereby resulting in the non-significant result.

In this study, majority of the participants appreciated the flexibility that telecommuting offered in terms of working hours and location. This provided them with a sense of autonomy and control by allowing them the opportunity to choose the time and place that bolster productivity. This is also aligned with the findings from Brunelle and Fortin (2021), which found that telecommuters experienced greater satisfaction of their need for autonomy than office workers. Additionally, given that participants were not required to travel to their office, participants appreciated that time and money were saved on transportation.

Consistent with literature findings, there was an effect of caregiving duties on telecommuting, especially for female officers. While caregivers identified flexibility and family time as pros of telecommuting, there were also compromises in areas such as productivity, work-life separation, and conduciveness - this was further proven with the strong correlation between feelings of satisfaction with telecommuting and other domains like productivity, conducive work environment, work-life-related domains, and stress-related domains. In this study, nearly $30 \%$ of caregivers listed their home environment as the biggest challenge with telecommuting, and a resulting 
effect on reduced productivity. This tied in with Kossek et al.'s (2006) study, which found that individuals who integrate work and personal life tended to experience more role conflict due to their need to juggle various responsibilities. Due to such challenges, caregivers reported that they felt less supported by and connected to their supervisors and required more understanding that their deliverables may be delayed.

On the contrary, analyses also found that male officers with no caregiving duties were shown to report lower levels of productivity and conducive environment, hence leading to reporting lower levels of satisfaction. These findings counter numerous studies showing that females and caregivers (whether females or males) suffer greater negative consequences when telecommuting. The findings may be unique to the COVID-19 context. A survey conducted by Deloitte (Patty and Wade 2020) found that women working from home during the pandemic were better at adapting and more satisfied with the telecommuting experience. Constant interactions with their loved ones provided them with a sense of security and safety and allowed them to be present during important events or appointments. This may further explain why male caregivers are less affected by their unfavorable experiences as compared to non-caregivers; their negative perceptions are buffered by the benefits of staying at home and spending time with their children and loved ones. An alternative explanation for this may be due to the makeup of the individuals comprising male non-caregivers. In Singapore, male youths are mandated to serve the country (i.e., National Service) for 2 years. Male youths serving in the Singapore Police's staff departments would usually complete tasks on desktops in the office. Given the sudden telecommuting implementation, these individuals may not have had sufficient time to retrieve work laptops that would allow them access to vital software to complete their tasks, thereby resulting in decreased production and conduciveness. Given the unique findings, future studies should be conducted to elucidate this phenomenon.

Given the developments with COVID-19 and rapidly increasing infection numbers, participants unanimously agreed that telecommuting provided them with a peace of mind, where they felt safe from the risk of infection. This is aligned with the findings from Mansilla Domínguez et al. (2020), which found a lower perceived risk of COVID-19 infection when working from home as compared to working outside the home among the Spanish population. By working from home, participants would be less exposed to the virus and minimize the overall risk of infection. It was noteworthy that significant decreases in feelings of safety, poorer stress management, and increased stress levels were reported during the third week of the study. This could be due to two possible reasons. First, there was a sudden escalation in the number of infected cases during the third week, with the number of new cases crossing 1,000 for the first time. This may have led to the decreased sense of safety reported as participants' concern regarding contracting the virus intensified. Second, Circuit Breaker measures were extended during that week. This announcement may have impacted officers' stress management and levels of stress as they were mentally unprepared for the extension and were worried about coping with the extended lockdown.

Across all participants, technological and logistical issues were consistently identified as key areas that were challenging and required improvement. Research has shown that fewer work-related interruptions-particularly IT interruptionsimprove productivity (Boshua et al. 2017). Considering the sensitive nature of work that police officers handle, participants reported that the inability to access programs and databases affected their ability to work effectively. Additionally, breakdowns in connectivity disrupted communications with colleagues or clients were highlighted as sore points. Officers noted difficulties with working due to the lack of necessary logistics (i.e., desktop screen, printers, headsets). These culminated in lower levels of satisfaction with telecommuting and productivity. This is aligned with Nguyen's (2021) findings that difficulties in accessing data negatively influenced the perception of telecommuting for a group of telecommuters in Vietnam during a COVID-19 lockdown.

This study had inherent limitations that can be improved in subsequent studies. First, the data was obtained via an anonymous survey. This anonymity resulted in the inability to track participants and the individual effects of prolonged telecommuting, thereby equating to the valuable loss of data which could have offered more insight and improved accuracy of the findings. Additionally, as some officers could return to the office for essential services, respondents may have returned to office on selected days. The results did not account for such individuals, resulting in a possible dilution of the effects of prolonged telecommuting (i.e., these individuals should not be considered as having participated in prolonged telecommuting). Future studies may consider designing a non-anonymous longitudinal study to strengthen their findings and better ascertain the effects of telecommuting.

Second, there may be a difference between perceived productivity and actual productivity. The vagueness of the term, coupled with the lack of a tangible value for output, meant that there was a subjective interpretation of the definition of productivity. Therefore, while participants may have felt that they were less productive in comparison to pre-COVID-19 days, this may not actually be the case. To ensure that there is congruence between perceived and actual productivity, future studies may consider including supervisors into their pool of participants to assess if subordinates' perceived levels of productivity match their supervisors'. This can help to close the gap between perceived and actual productivity.

Finally, considering the climate during which this study was conducted (i.e., COVID-19), the findings is limited in its 
generalizability. During the time of the study, telecommuting was mandated by the government and citizens were not allowed to breach the restrictions imposed. The findings may not be reflective of situations during which telecommuting is an option as opposed to an order and should be interpreted with prudence. As such, follow-up studies could replicate this study on participants telecommuting during peace time when individuals are allowed to telecommute at their own discretion to validate the results.

\section{Recommendations}

With the issues at hand, organizational and management support may play a crucial role in diminishing the overall negative effects of telecommuting. To maximize the effectiveness of telecommuting implementation, several areas should be taken into consideration. Firstly, organizations should consider if employees have access to the necessary technology and logistics to complete their work. If these are not met, organizations should provide the basic resources to enable effective telecommuting. Secondly, personal and household characteristics should also be assessed. This would refer to the employees' ability to work independently and whether other dependents are present in their workspace. Should there be concerns with these considerations, it is imperative that leaders/managers take on a more empathic approach when communicating with their subordinates. This may be by displaying more trust, as well as understanding that deliverables may be delayed. Communication is fundamental in any relationship. Similarly, managers should communicate frequently with their subordinates to continually assess how their subordinates are coping and what additional support is required (Lautsch et al. 2009; Bentley et al. 2016).

To optimize the success of telecommuting, choosing the right communication tools is important. Tools that can simulate face-to-face interactions are generally preferred (Waber 2013). Video tools thus have an edge over email. Informal video tools that mimic "watercooler" conversations (e.g., Google Hangouts) are preferred as compared to professional tools (e.g., Skype).

The circumstance in which this study was conducted was unique. As part of the Singapore government's initiatives to reduce the number of COVID-19 positive cases, participants were required to work from home to minimize exposure. As evidenced from the abundant literature, telecommuting has been proven to have both beneficial and detrimental effects (Raghuram and Wiesenfeld 2004; Boshua et al. 2017; Grant et al. 2013; Mann et al. 2000). Due to the prolonged nature of telecommuting at the time of the study, the adverse impacts on well-being may be exacerbated. Individuals should therefore be equipped with techniques on how to cope with the stressors associated with telecommuting.

While working from home, individuals may experience difficulties in separating work and personal life. Setting boundaries may be an efficient way to ensure the segregation of work and family in both time and space. This can be done by organizing expectations and role demands into distinct home and work domains. For example, individuals may practice (1) turning off the work phone at the end of the day, (2) avoid answering work-related messages or calls unless urgent (if not in possession of a work phone), and (3) have an allocated work space (i.e., home office) with the door kept closed to reduce interruptions from the family (Kossek et al. 2006).

Loose boundaries may also have implications on individuals' leisure times. The inability to "switch off" from work may cause individuals to over-work and have lesser recuperation time (Hartig et al. 2007; Grant et al. 2013). Individuals should take on a structured approach by having clear routines for each portion of the day (i.e., morning, afternoon, and evening). For example, mornings could be dedicated to clearing emails, afternoons for daily to-do lists, and evenings for rest. When working from home, individuals should have clear start and end times for work (e.g., 9 a.m. to 6 p.m.) and set "work" and "break" times throughout the day (Airtasker 2020).

Individuals may sometimes forego their basic needs. Although intuitive, individuals should also ensure that their basic needs and well-being are met. Tapping on the aforementioned paragraph, individuals can extend regularity and structure to their mealtimes, sleep schedule, and exercise plans. To prevent social isolation from setting in, individuals should also set regular social contact time with family and friends. These meetings could take place virtually (e.g., via ZOOM, Skype, Houseparty).

In conclusion, this study found that the effects of telecommuting in a police agency differed based on the presence of caregiving duties. Participants who are also caregivers experienced more difficulties in times of prolonged telecommuting. As such, the suitability of remote working arrangements should be carefully assessed, with the relevant support rendered where necessary. 


\section{Appendix}

Table 1 Breakdown of participants

\begin{tabular}{lllllll}
\hline Week & \multicolumn{1}{l}{ Gender } & & & Caregiving & Total \\
\cline { 2 - 3 } & Male & Female & & Caregiver & Non-caregiver & \\
\hline Week 1 (9 April 2020) & $320(57.6 \%)$ & $236(42.4 \%)$ & & $329(59.2 \%)$ & $227(40.8 \%)$ & 556 \\
Week 2 (16 April 2020) & $300(55.4 \%)$ & $242(44.6 \%)$ & & $299(55.2 \%)$ & $243(44.8 \%)$ & 542 \\
Week 3 (23 April 2020) & $307(59.7 \%)$ & $207(40.3 \%)$ & & $279(54.3 \%)$ & $235(45.7 \%)$ & 514 \\
Week 4 (30 April 2020) & $240(58.3 \%)$ & $171(41.7 \%)$ & & $215(52.2 \%)$ & $197(47.8 \%)$ & 412 \\
\hline
\end{tabular}

Table 2 Descriptive statistics for gender and caregiver role on respective domains

\begin{tabular}{|c|c|c|c|c|c|c|c|c|c|c|c|c|c|}
\hline \multirow[t]{3}{*}{$\mathrm{S} / \mathrm{N}$} & \multirow[t]{3}{*}{ Domain } & \multicolumn{6}{|l|}{ Male } & \multicolumn{6}{|c|}{ Female } \\
\hline & & \multicolumn{3}{|c|}{ Caregivers } & \multicolumn{3}{|c|}{ Non-caregivers } & \multicolumn{3}{|c|}{ Caregivers } & \multicolumn{3}{|c|}{ Non-caregivers } \\
\hline & & Mean & SD & $\mathrm{N}$ & Mean & SD & $\mathrm{N}$ & Mean & SD & $\mathrm{N}$ & Mean & SD & $\mathrm{N}$ \\
\hline 1. & Productivity* & 3.39 & 0.04 & 693 & 3.53 & 0.04 & 473 & 3.40 & 0.04 & 430 & 3.73 & 0.05 & 427 \\
\hline 2. & Distraction & 2.92 & 1.14 & 693 & 2.49 & 1.07 & 473 & 2.86 & 1.04 & 430 & 2.41 & 1.02 & 427 \\
\hline 3. & Length of working hours* & 3.39 & 1.11 & 693 & 3.21 & 1.10 & 473 & 3.54 & 1.03 & 430 & 3.59 & 1.04 & 427 \\
\hline 4. & Conduciveness* & 3.15 & 1.13 & 488 & 3.23 & 0.98 & 358 & 3.10 & 0.96 & 306 & 3.43 & 0.93 & 315 \\
\hline 5. & Connectedness (Colleagues) & 3.33 & 1.01 & 693 & 3.32 & 0.99 & 473 & 3.29 & 0.97 & 430 & 3.40 & 0.92 & 427 \\
\hline 6. & Connectedness (Supervisors) & 3.36 & 1.03 & 693 & 3.44 & 0.91 & 473 & 3.26 & 0.99 & 430 & 3.37 & 0.96 & 427 \\
\hline 7. & Supported (Colleagues) & 3.74 & 0.93 & 693 & 3.80 & 0.86 & 473 & 3.64 & 0.84 & 430 & 3.77 & 0.89 & 427 \\
\hline 8. & Supported (Supervisors) & 3.72 & 0.96 & 693 & 3.84 & 0.85 & 473 & 3.53 & 0.90 & 430 & 3.69 & 0.91 & 427 \\
\hline 9. & Work-life separation & 3.48 & 1.10 & 693 & 3.73 & 0.96 & 473 & 3.47 & 1.01 & 430 & 3.70 & 0.99 & 427 \\
\hline 10. & Work-life effectiveness & 3.61 & 1.08 & 693 & 3.74 & 0.96 & 473 & 3.53 & 0.98 & 430 & 3.78 & 0.96 & 427 \\
\hline 11. & Stress management & 3.62 & 0.99 & 693 & 3.74 & 0.90 & 473 & 3.52 & 0.97 & 430 & 3.71 & 0.92 & 427 \\
\hline 12. & Stress level & 3.44 & 1.05 & 488 & 3.64 & 1.04 & 358 & 3.33 & 1.05 & 306 & 3.50 & 0.99 & 315 \\
\hline 13. & Safety (from risk of infection)* & 4.20 & 1.02 & 692 & 4.26 & 0.90 & 473 & 4.20 & 0.92 & 430 & 4.49 & 0.72 & 427 \\
\hline 14. & Satisfaction* & 3.84 & 0.94 & 692 & 3.95 & 0.88 & 473 & 3.79 & 0.80 & 429 & 4.08 & 0.77 & 427 \\
\hline
\end{tabular}

$* p<0.05$

Table 3 Descriptive statistics for caregiver role on respective domains

\begin{tabular}{|c|c|c|c|c|c|c|c|}
\hline \multirow[t]{2}{*}{$\mathrm{S} / \mathrm{N}$} & \multirow[t]{2}{*}{ Domain } & \multicolumn{3}{|c|}{ Caregivers } & \multicolumn{3}{|c|}{ Non-caregivers } \\
\hline & & Mean & SD & $\mathrm{N}$ & Mean & SD & $\mathrm{N}$ \\
\hline 1. & Productivity* & 3.39 & 0.93 & 1123 & 3.62 & 0.92 & 900 \\
\hline 2 & Distraction* & 2.89 & 1.10 & 1123 & 2.45 & 1.05 & 900 \\
\hline 3. & Length of working hours & 3.45 & 1.08 & 1123 & 3.39 & 1.09 & 900 \\
\hline 4. & Conduciveness* & 3.13 & 1.07 & 794 & 3.32 & 0.96 & 673 \\
\hline 5. & Connectedness (Colleagues) & 3.32 & 0.10 & 1123 & 3.36 & 0.96 & 900 \\
\hline 6. & Connectedness (Supervisors)* & 3.32 & 1.02 & 1123 & 3.41 & 0.93 & 900 \\
\hline 7. & Supported (Colleagues)* & 3.70 & 0.89 & 1123 & 3.79 & 0.87 & 900 \\
\hline 8. & Supported (Supervisors)* & 3.65 & 0.94 & 1123 & 3.77 & 0.88 & 900 \\
\hline 9. & Work-life separation* & 3.48 & 1.07 & 1123 & 3.72 & 0.97 & 900 \\
\hline 10. & Work-life effectiveness* & 3.58 & 1.04 & 1123 & 3.76 & 0.96 & 900 \\
\hline 11. & Stress management* & 3.58 & 0.99 & 1123 & 3.73 & 0.91 & 900 \\
\hline 12. & Stress level* & 3.39 & 1.05 & 794 & 3.57 & 1.02 & 673 \\
\hline 13. & Safety (from risk of infection)* & 4.20 & 0.98 & 1122 & 4.37 & 0.83 & 900 \\
\hline 14. & Satisfaction* & 3.82 & 0.89 & 1122 & 4.01 & 0.83 & 900 \\
\hline
\end{tabular}

$* p<0.05$ 
Table 4 Analysis of variance for productivity

\begin{tabular}{llcll}
\hline Source & df & Mean square & F & Sig \\
\hline Caregiver & 1 & 26.67 & 31.42 & 0.00 \\
Gender & 1 & 5.41 & 6.64 & 0.01 \\
Caregiver $\times$ gender & 1 & 4.75 & 5.59 & 0.02 \\
Error & 2019 & 0.85 & & \\
\hline
\end{tabular}

Table 5 Analysis of variance for distraction

\begin{tabular}{llcrl}
\hline Source & df & Mean Square & F & Sig \\
\hline Caregiver & 1 & 92.36 & 79.58 & 0.00 \\
Gender & 1 & 2.12 & 1.83 & 0.18 \\
Caregiver $\times$ gender & 1 & 0.03 & 0.03 & 0.87 \\
Error & 2019 & 1.16 & & \\
\hline
\end{tabular}

Table 6 Analysis of variance for length of working hours

\begin{tabular}{|c|c|c|c|c|}
\hline Source & $\mathrm{df}$ & Mean s & $\mathrm{F}$ & Sig \\
\hline Caregiver & 1 & 2.08 & 1.80 & 0.18 \\
\hline Gender & 1 & 34.77 & 30.09 & 0.00 \\
\hline Caregiver $\times$ gender & 1 & 6.03 & 5.22 & 0.02 \\
\hline Error & 2019 & 1.16 & & \\
\hline
\end{tabular}

Table 7 Analysis of variance for conduciveness

\begin{tabular}{lllll}
\hline Source & df & Mean square & F & Sig \\
\hline Caregiver & 1 & 14.59 & 14.07 & 0.00 \\
Gender & 1 & 2.18 & 2.10 & 0.15 \\
Caregiver $\times$ gender & 1 & 5.76 & 5.56 & 0.02 \\
Error & 1463 & 1.04 & & \\
\hline
\end{tabular}

Table 8 Analysis of variance for connectedness (colleagues)

\begin{tabular}{lllll}
\hline Source & df & Mean square & F & Sig \\
\hline Caregiver & 1 & 1.17 & 1.22 & 0.27 \\
Gender & 1 & 0.20 & 0.21 & 0.65 \\
Caregiver $\times$ gender & 1 & 1.94 & 2.02 & 0.16 \\
Error & 2019 & 0.96 & & \\
\hline
\end{tabular}

Table 9 Analysis of variance for connectedness (supervisors)

\begin{tabular}{lllll}
\hline Source & df & Mean square & F & Sig \\
\hline Caregiver & 1 & 5.14 & 5.35 & 0.02 \\
Gender & 1 & 3.36 & 3.49 & 0.06 \\
Caregiver $\times$ gender & 1 & 0.09 & 0.10 & 0.76 \\
Error & 2019 & 0.96 & & \\
\hline
\end{tabular}

Table 10 Analysis of variance for supportedness (colleagues)

\begin{tabular}{lllll}
\hline Source & df & Mean square & F & Sig \\
\hline Caregiver & 1 & 4.15 & 5.31 & 0.02 \\
Gender & 1 & 2.17 & 2.78 & 0.10 \\
Caregiver $\times$ gender & 1 & 0.42 & 0.53 & 0.47 \\
Error & 2019 & 0.78 & & \\
\hline
\end{tabular}

Table 11 Analysis of variance for supportedness (supervisors)

\begin{tabular}{llccc}
\hline Source & df & Mean square & F & Sig \\
\hline Caregiver & 1 & 9.71 & 11.64 & 0.00 \\
Gender & 1 & 15.18 & 18.19 & 0.00 \\
Caregiver $\times$ gender & 1 & 0.18 & 0.22 & 0.64 \\
Error & 2019 & 0.83 & & \\
\hline
\end{tabular}

Table 12 Analysis of variance for work-life separation

\begin{tabular}{llrrl}
\hline Source & df & Mean square & \multicolumn{1}{l}{ F } & Sig \\
\hline Caregiver & 1 & 28.77 & 27.18 & 0.00 \\
Gender & 1 & 0.16 & 0.15 & 0.70 \\
Caregiver $\times$ gender & 1 & 0.08 & 0.08 & 0.79 \\
Error & 2019 & 1.06 & & \\
\hline
\end{tabular}

Table 13 Analysis of variance for work-life effectiveness

\begin{tabular}{llcrl}
\hline Source & df & Mean square & F & Sig \\
\hline Caregiver & 1 & 16.86 & 16.60 & 0.00 \\
Gender & 1 & 0.18 & 0.17 & 0.68 \\
Caregiver $\times$ gender & 1 & 1.68 & 1.65 & 0.20 \\
Error & 2019 & 1.02 & & \\
\hline
\end{tabular}


Table 14 Analysis of variance for stress management

\begin{tabular}{llcrl}
\hline Source & df & Mean square & \multicolumn{1}{l}{ F } & Sig \\
\hline Caregiver & 1 & 11.86 & 13.09 & 0.00 \\
Gender & 1 & 2.07 & 2.29 & 0.13 \\
Caregiver $\times$ gender & 1 & 0.76 & 0.84 & 0.36 \\
Error & 2019 & 0.91 & & \\
\hline
\end{tabular}

Table 15 Analysis of variance for stress level

\begin{tabular}{llcrl}
\hline Source & df & Mean square & \multicolumn{1}{l}{ F } & Sig \\
\hline Caregiver & 1 & 11.86 & 11.10 & 0.00 \\
Gender & 1 & 5.64 & 5.28 & 0.02 \\
Caregiver $\times$ gender & 1 & 0.16 & 0.15 & 0.70 \\
Error & 1463 & 1.07 & &
\end{tabular}

Table 17 Analysis of variance for satisfaction

\begin{tabular}{llcrl}
\hline Source & df & Mean square & \multicolumn{1}{l}{ F } & Sig \\
\hline Caregiver & 1 & 18.83 & 25.18 & 0.00 \\
Gender & 1 & 0.97 & 1.29 & 0.26 \\
Caregiver $\times$ gender & 1 & 3.75 & 5.02 & 0.03 \\
Error & 2017 & 0.75 & & \\
\hline
\end{tabular}

Table 18 Descriptive statistics for length of weeks on respective domains

\begin{tabular}{|c|c|c|c|c|c|c|c|c|c|c|c|c|c|}
\hline \multirow[t]{2}{*}{$\mathrm{S} / \mathrm{N}$} & \multirow[t]{2}{*}{ Domain } & \multicolumn{3}{|c|}{ Week 1} & \multicolumn{3}{|c|}{ Week 2} & \multicolumn{3}{|c|}{ Week 3} & \multicolumn{3}{|c|}{ Week 4} \\
\hline & & Mean & SD & $\mathrm{N}$ & Mean & SD & $\mathrm{N}$ & Mean & SD & $\mathrm{N}$ & Mean & SD & $\mathrm{N}$ \\
\hline 1. & Productivity & 3.50 & 0.92 & 556 & 3.50 & 0.92 & 542 & 3.47 & 0.91 & 513 & 3.52 & 0.91 & 412 \\
\hline 2. & Distraction & 2.64 & 1.17 & 556 & 2.66 & 1.09 & 542 & 2.76 & 1.06 & 279 & 2.75 & 1.05 & 412 \\
\hline 3. & Length of working hours & 3.35 & 1.14 & 556 & 3.44 & 1.09 & 542 & 3.48 & 1.04 & 513 & 3.42 & 1.04 & 412 \\
\hline 4. & Conduciveness & & & & 3.20 & 1.03 & 542 & 3.17 & 1.01 & 513 & 3.32 & 1.03 & 412 \\
\hline 5. & Connectedness (Colleagues) & 3.35 & 1.00 & 556 & 3.30 & 0.99 & 542 & 3.31 & 0.95 & 513 & 3.40 & 0.96 & 412 \\
\hline 6. & Connectedness (Supervisors) & 3.35 & 1.03 & 556 & 3.33 & 0.98 & 542 & 3.36 & 0.94 & 513 & 3.41 & 0.96 & 412 \\
\hline 7. & Supported (Colleagues) & 3.77 & 0.87 & 556 & 3.74 & 0.88 & 542 & 3.71 & 0.90 & 513 & 3.75 & 0.88 & 412 \\
\hline 8. & Supported (Supervisors) & 3.74 & 0.94 & 556 & 3.69 & 0.93 & 542 & 3.69 & 0.91 & 513 & 3.68 & 0.90 & 412 \\
\hline 9. & Work-life separation & 3.59 & 1.04 & 556 & 3.61 & 1.06 & 542 & 3.55 & 1.04 & 513 & 3.59 & 1.00 & 412 \\
\hline 10. & Work-life effectiveness & 3.72 & 1.02 & 556 & 3.70 & 1.02 & 542 & 3.58 & 1.02 & 513 & 3.62 & 0.98 & 412 \\
\hline 11. & Stress management & $3.71 *$ & 0.97 & 556 & 3.67 & 0.97 & 542 & $3.55^{*}$ & 0.94 & 513 & 3.67 & 0.93 & 412 \\
\hline 12. & Stress level & & & & $3.54 *$ & 1.07 & 542 & $3.37 *$ & 1.03 & 513 & $3.54^{*}$ & 1.00 & 412 \\
\hline 13. & Safety & $4.42 *$ & 0.87 & 556 & 4.28 & 0.94 & 541 & $4.16^{*}$ & 0.93 & 513 & $4.23^{*}$ & 0.93 & 412 \\
\hline 14. & Satisfaction & 3.95 & 0.84 & 556 & 3.91 & 0.87 & 541 & 3.86 & 0.88 & 513 & 3.90 & 0.90 & 412 \\
\hline
\end{tabular}

${ }^{*} p<0.005$.

Table 19 Analysis of variance for stress management

\begin{tabular}{llcrl}
\hline Source & df & Mean square & \multicolumn{1}{l}{ F } & Sig \\
\hline Week & 3 & 2.44 & 2.70 & 0.05 \\
Caregiver & 1 & 10.64 & 11.77 & 0.00 \\
Week $\times$ caregiver & 3 & 0.45 & 0.50 & 0.68 \\
Error & 2015 & 0.90 & & \\
\hline
\end{tabular}

Table 16 Analysis of variance for safety

\begin{tabular}{lllll}
\hline Source & df & Mean square & \multicolumn{1}{l}{ F } & Sig \\
\hline Caregiver & 1 & 14.98 & 17.99 & 0.00 \\
Gender & 1 & 6.75 & 8.10 & 0.00 \\
Caregiver $\times$ gender & 1 & 6.58 & 7.90 & 0.01 \\
Error & 2018 & 0.83 & & \\
\hline
\end{tabular}


Table 21 Analysis of variance for safety

\begin{tabular}{llcrl}
\hline Source & df & Mean square & F & Sig \\
\hline Week & 3 & 6.30 & 7.60 & 0.00 \\
Caregiver & 1 & 14.50 & 17.50 & 0.00 \\
Week $\times$ car- & 3 & 1.27 & 1.53 & 0.20 \\
$\quad$ egiver & & & & \\
Error & 2014 & 0.83 & &
\end{tabular}

Table 22 Analysis of variance for productivity

\begin{tabular}{llcrl}
\hline Source & df & Mean square & \multicolumn{1}{l}{ F } & Sig \\
\hline Week & 3 & 0.18 & 0.21 & 0.89 \\
Caregiver & 1 & 25.26 & 29.58 & 0.00 \\
Week $\times$ caregiver & 3 & 0.74 & 0.86 & 0.46 \\
Error & 2015 & 0.85 & & \\
\hline
\end{tabular}

Table 23 Analysis of variance for distraction

\begin{tabular}{llcrl}
\hline Source & df & Mean square & \multicolumn{1}{l}{ F } & Sig \\
\hline Week & 3 & 2.44 & 2.11 & 0.10 \\
Caregiver & 1 & 99.25 & 85.58 & 0.00 \\
Week $\times$ caregiver & 3 & 0.19 & 0.16 & 0.92 \\
Error & 2015 & 1.16 & & \\
\hline
\end{tabular}

Table 24 Analysis of variance for length of working hours

\begin{tabular}{lllll}
\hline Source & df & Mean square & F & Sig \\
\hline Week & 3 & 1.43 & 1.22 & 0.30 \\
Caregiver & 1 & 2.70 & 2.31 & 0.13 \\
Week $\times$ caregiver & 3 & 2.61 & 2.23 & 0.08 \\
Error & 2015 & 1.17 & & \\
\hline
\end{tabular}

Table 25 Analysis of variance for conduciveness

\begin{tabular}{llcrl}
\hline Source & df & Mean square & \multicolumn{1}{l}{ F } & Sig \\
\hline Week & 2 & 2.34 & 2.25 & 0.11 \\
Caregiver & 1 & 12.16 & 11.69 & 0.00 \\
Week $\times$ caregiver & 2 & 0.32 & 0.31 & 0.73 \\
Error & 1461 & 1.04 & & \\
\hline
\end{tabular}

Table 26 Analysis of variance for connectedness (colleagues)

\begin{tabular}{lllll}
\hline Source & df & Mean square & F & Sig \\
\hline Week & 3 & 0.97 & 1.01 & 0.39 \\
Caregiver & 1 & 0.87 & 0.90 & 0.34 \\
Week $\times$ caregiver & 3 & 0.85 & 0.89 & 0.45 \\
Error & 2015 & 0.96 & & \\
\hline
\end{tabular}

Table 27 Analysis of variance for connectedness (supervisors)

\begin{tabular}{lllll}
\hline Source & df & Mean square & F & Sig \\
\hline Week & 3 & 0.57 & 0.59 & 0.62 \\
Caregiver & 1 & 3.82 & 3.97 & 0.05 \\
Week $\times$ caregiver & 3 & 0.91 & 0.95 & 0.42 \\
Error & 2015 & 0.96 & & \\
\hline
\end{tabular}

Table 28 Analysis of variance supportedness (colleagues)

\begin{tabular}{lllll}
\hline Source & df & Mean square & F & Sig \\
\hline Week & 3 & 0.31 & 0.39 & 0.76 \\
Caregiver & 1 & 3.28 & 4.20 & 0.04 \\
Week $\times$ caregiver & 3 & 0.44 & 0.57 & 0.64 \\
Error & 2015 & 0.78 & & \\
\hline
\end{tabular}

Table 29 Analysis of variance supportedness (supervisors)

\begin{tabular}{lllll}
\hline Source & df & Mean square & F & Sig \\
\hline Week & 3 & 0.388 & 0.461 & 0.710 \\
Caregiver & 1 & 7.181 & 8.527 & 0.004 \\
Week $\times$ caregiver & 3 & 0.740 & 0.879 & 0.451 \\
Error & 2015 & 0.842 & & \\
\hline
\end{tabular}

Table 30 Analysis of variance for work-life separation

\begin{tabular}{llcrl}
\hline Source & df & Mean square & \multicolumn{1}{c}{ F } & Sig \\
\hline Week & 3 & 0.45 & 0.42 & 0.73 \\
Caregiver & 1 & 28.60 & 26.99 & 0.00 \\
Week $\times$ caregiver & 3 & 0.46 & 0.43 & 0.73 \\
Error & 2015 & 1.06 & & \\
\hline
\end{tabular}

Table 31 Analysis of variance for work-life effectiveness

\begin{tabular}{llcrl}
\hline Source & df & Mean square & \multicolumn{1}{c}{ F } & Sig \\
\hline Week & 3 & 2.14 & 2.11 & 0.10 \\
Caregiver & 1 & 15.82 & 15.59 & 0.00 \\
Week $\times$ caregiver & 3 & 0.41 & 0.40 & 0.75 \\
Error & 2015 & 1.02 & & \\
\hline
\end{tabular}

Table 32 Analysis of variance for satisfaction

\begin{tabular}{llcrl}
\hline Source & df & Mean square & \multicolumn{1}{c}{ F } & Sig \\
\hline Week & 3 & 0.60 & 0.80 & 0.49 \\
Caregiver & 1 & 18.34 & 24.52 & 0.00 \\
Week $\times$ caregiver & 3 & 1.49 & 1.99 & 0.11 \\
Error & 2014 & 0.75 & & \\
\hline
\end{tabular}




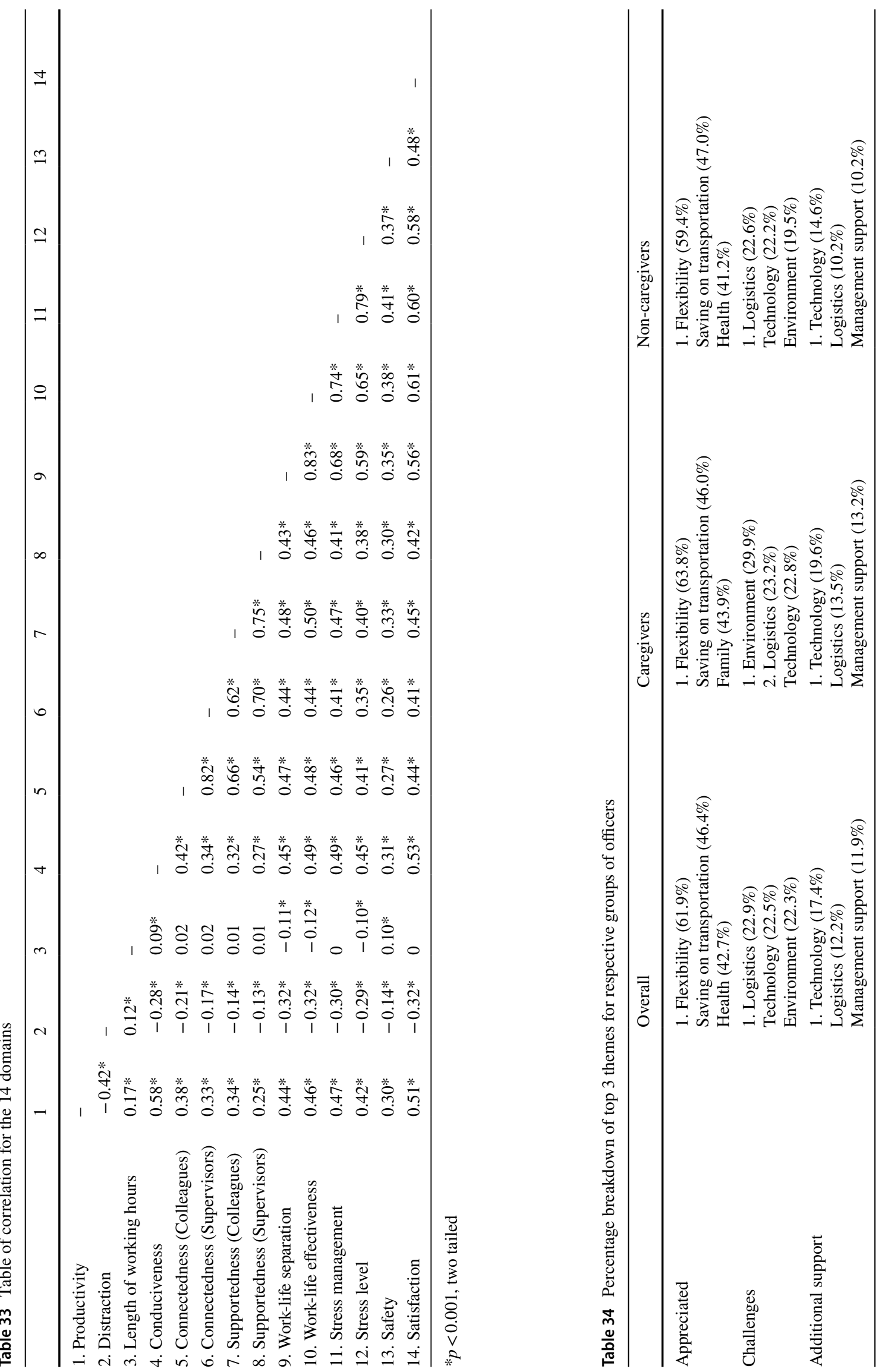




\section{References}

Airtasker (2020). The benefits of working from home. Airtasker. https://airtasker.com/blog/the-benefits-of-working-from-home

Allen TD, Golden TD, Shockley KM (2015) How effective is telecommuting? Assessing the status of our scientific findings. Psychol Sci Public Interest 16(2):40-68. https://doi.org/10.1177/ 1529100615593273

Allvin M, Aronsson G, Hagstrom T, Johansson G, Lundberg U (2011) Work without boundaries, psychological perspectives on the new working life. Wiley-Blackwell, Chichester. https://doi.org/10. 1002/9781119991236

Bentley T, Bosua R, Teo ST, Gloet M (2016) The role of organisational support in teleworker wellbeing: a socio-technical systems approach. Appl Ergon 52:207-215. https://doi.org/10.1016/j. apergo.2015.07.019

Boshua R, Kurnia S, Gloet M, Mendoza A (2017) Telework impact on productivity and well-being. In: Choudrie J (ed) Social Inclusion and Usability of ICT-Enabled Services, p Melbourne: Routledge, p 201-223. https://doi.org/10.4324/9781315677316

Braun V, Clarke V (2006) Using thematic analysis in psychology. Qual Res Psychol 3:77-101. https://doi.org/10.1191/1478088706qp063oa

Brunelle E, Fortin J (2021) Distance makes the heart grow fonder: an examination of teleworkers' and office workers' job satisfaction through the lens of self-determination theory. SAGE Open 11(1):215824402098551. https://doi.org/10.1177/2158244020985516

Delanoeije J, Verbruggen M, Germeys L (2019) Boundary role transitions: a day-to-day approach to explain the effects of home-based telework on work-to-home conflict and home-to-work conflict. Hum Relat (new York) 72(12):1843-1868. https://doi.org/10. $1177 / 0018726718823071$

Elsbach K, Cable D (2012) Why showing your face at work matters. MIT Sloan Manag Rev 53(4):10-12

Eurofound and the International Labour Office (2017) Working anytime, anywhere: the effects on the world of work. Publications office of the European Union, Luxembourg, and the International Labour Office, Geneva

Gachter M, Savage DA, Torgler B (2011) Gender variations of physiological and psychological strain amongst police officers. Gender Issues 28:66-93. https://doi.org/10.1007/s12147-011-9100-9

Golden TD (2006) The role of relationships in understanding telecommuter satisfaction. J Organ Behav 27:319-340. https://doi.org/10. 1002/job.369

Golden TD, Veiga JF (2005) The impact of extent of telecommuting on job satisfaction: Resolving inconsistent findings. J Manag 31(2):301-318. https://doi.org/10.1177/0149206304271768

Golden TD, Eddleston KA (2020) Is there a price telecommuters pay? Examining the relationship between telecommuting and objective career success. J Vocat Behav 116:103348

Grant CA, Spurgeon P, Wallace LM (2013) An exploration of the psychological factors affecting remote e-worker's job effectiveness, well-being and work-life balance. Empl Relat 35(5):527-546. https://doi.org/10.11108/er-08-2012-0059

Grenny J, Maxfield D (2017) A study of 1,100 employees found that remote workers feel shunned and left out. Har Bus Rev. https:// hbr.org/2017/11/a-study-of-1100-employees-found-that-remoteworkers-feel-shunned-and-left-out

Harker MB, MacDonnell R (2012) Is telework effective for organizations? A meta-analysis of empirical research on perception of telework and organizational outcomes. Management Research Review 35(7):602-616. https://doi.org/10.1108/01409171211238820

Hartig T, Kylin C, Johansson G (2007) The Telework Tradeoff: Stress Mitigation vs. Constrained Restoration. Appl Psychol 56(2):231-253
Ipsen C, Kirchner K, Hansen JP (2020) Experiences of working from home in times of COVID-19: international survey conducted the first months of the national lockdowns March-May, 2020. Denmark: DTU, Department of Management

Kossek EE, Lautsch BA, Eaton SC (2006) Telecommuting, control, and boundary management: correlates of policy use and practice, job control and work-family effectiveness. J Vocat Behav 58:347-367. https://doi.org/10.1016/j.jvb.2005.07.002

Kraut RE (1989) Telecommuting: The Trade-offs of Home Work. Journal of Communication 39(3):19-47

Lautsch BA, Kossek EE, Eaton SC (2009) Supervisory approaches and paradoxes in managing telecommuting implementation. Human Relations 62:795-827. https://doi.org/10.1177/ 0018726709104543

Leslie LM, Manchester CF, Park TY, Mehng SA (2012) Flexible work practices: a source of career premiums or penalties? Acad Manag J 55(6):1407-1428. https://doi.org/10.5464/amj.2010.0651

Mann S, Varey R, Button W (2000) An exploration of the emotional impact of tele-working via computer-mediated communication. J Manag Psychol 15(7):668-690

Mansilla Domínguez JM, Font Jiménez I, Belzunegui Eraso A, Peña Otero D, Díaz Pérez D, Recio Vivas AM (2020) Risk perception of COVID-19 community transmission among the Spanish population. Int J Env Res Pub He 17(23):8967. https://doi.org/10. 3390/ijerph17238967

Manuyama T, Tietze S (2012) From anxiety to assurance: concerns and outcomes of telework. Pers Rev 41(4):450-469. https://doi.org/10. $1108 / 00483481211229375$

Mas A, Pallais A (2017) Valuing alternative work arrangements. Am Econ Rev 107(12):3722-3759. https://doi.org/10.1257/ aer. 20161500

Masuda AD, Holtschlag C, Nicklin JM (2017) Why the availability of telecommuting matters: the effects of telecommuting on engagement via goal pursuit. Career Dev Int 22(2):200-219. https://doi. org/10.1108/cdi-05-2016-0064

MH Nguyen (2021) Factors influencing home-based telework in Hanoi (Vietnam) during and after the COVID-19 era Transportation 1-32

O' Keefe P, Caulfield B, Brazil W, White P (2016) The impacts of telecommuting in Dublin. Res Transp Econ 57:13-20. https://doi. org/10.1016/j.retrec.2016.06.010

Ojala S (2011) Supplemental work at home among finnish wage warners: involuntary overtime or taking the advantage of flexibility? Nord J of Work Life Stud 1(2):77

Patty A, Wade M (2020) 'They know the drill': women happier working from home than men. The Sydney Morning Herald. https://www. smh.com.au/business/workplace/they-know-the-drill-womenhappier-working-from-home-than-men-20201026-p568pw.html

Putro SS, Riyanto S (2020) How Asian sandwich generation managing stress in telecommuting during COVID-19 pandemic. Int J Sci Res Eng Dev 3(3):485-492

Raghuram S (2014) Telecommuting in India: pitfalls and possibilities. SA J Hum Res Manag 1(2):207-220. https://doi.org/10.1177/ 2322093714549108

Raghuram S, Wiesenfeld B (2004) Work-nonwork conflict and job stress among virtual workers. Hum Res Manag 43:259-277. https://doi.org/10.1002/hrm.20019

Sarbu M (2018) The role of telecommuting for work-family conflict among German employees. Res Transp Econ 70:36-51. https:// doi.org/10.1016/j.retrec.2018.07.009

Sawilowsky S (2009) New effect size rules of thumb. J Mod Appl Stat Methods 8(2):597-599. https://doi.org/10.22237/jmasm/1257035100

Sullivan C (2012) Remote working and work-life balance. Work and Quality of Life. Psychology Press, London, pp 143-162 
Waber BN (2013) People analytics. Upper Saddle River, NJ: Pearson Education

Zia A, Bilal H (2017) Impact of telecommuting on the financial and social life of telecommuters in Pakistan. Pakistan Econ Soc Rev 55(1):185-199
Publisher's Note Springer Nature remains neutral with regard to jurisdictional claims in published maps and institutional affiliations. 